\title{
Cushing syndrome in pregnancy, diagnosed after delivery
}

\author{
Han Byul Kim ${ }^{1}$, Mi Kyung Kim ${ }^{2}$, El Kim ${ }^{3}$, Keun Soo Ahn ${ }^{4}$, Hye Soon Kim², Nam Kyung Kim ${ }^{5}$ \\ ${ }^{1}$ Division of Endocrinology and Metabolism, Department of Internal Medicine, Raphael Hospital, Daegu, Korea \\ ${ }^{2}$ Division of Endocrinology and Metabolism, Department of Internal Medicine, Keimyung University Dongsan Hospital, Daegu, Korea \\ ${ }^{3}$ Department of Neurosurgery, Keimyung University Dongsan Hospital, Daegu, Korea \\ ${ }^{4}$ Department of Surgery, Keimyung University Dongsan Hospital, Daegu, Korea \\ ${ }^{5}$ Park Kyung Dae Clinic of Internal Medicine, Gyeongju, Korea
}

Received: April 21, 2020

Revised: May 11, 2020

Accepted: May 12, 2020

Corresponding author:

Hye Soon Kim

Division of Endocrinology and

Metabolism, Department of Internal

Medicine, Keimyung University

Dongsan Hospital, 56 Dalseong-ro,

Jung-gu, Daegu 41931, Korea

Tel: +82-53-258-2982

Fax: +82-53-258-7982

E-mail:hsh12@dsmc.or.kr
Cushing syndrome (CS) is rare in pregnancy, and few cases have been reported to date. Women with untreated CS rarely become pregnant because of the ovulatory dysfunction induced by hypercortisolism. It is difficult to diagnose CS in pregnancy because of its very low incidence, the overlap between the clinical signs of hypercortisolism and the physiological changes that occur during pregnancy and the changes in hypothalamus-pituitary-adrenal axis activity that occur during pregnancy and limit the value of standard diagnostic testing. However, CS in pregnancy is associated with poor maternal and fetal outcomes; therefore, its early diagnosis and treatment are important. Here, we report two patients with CS that was not diagnosed during pregnancy, in whom maternal and fetal morbidity developed because of hypercortisolism.

Keywords: Complication; Cushing syndrome; Hypercortisolism; Pregnancy

\section{Introduction}

Cushing syndrome (CS) is rare in pregnancy, with only about 220 cases having been reported to date. Women with untreated CS rarely become pregnant because $\mathrm{CS}$ is associated with a high prevalence of ovulatory disturbances, which are induced by cortisol excess [1]. Furthermore, even if pregnancy occurs, hypercortisolism is associated with higher incidences of maternal and fetal complications; therefore, the early diagnosis and treatment of CS are important [2]. Here, we report two cases of CS that was diagnosed within the 12 months following delivery.

\section{Cases}

This study was approved by the Institutional Review Board of the Keimyung University Dongsan Hospital (IRB No: 2020-05-007).

\section{Case 1}

A 37-year-old women presented with bilateral flank pain and weight gain. She became pregnant in 2013 and underwent cesarean section at 35 weeks of gestation because of pulmonary arterial hypertension. A 1,720-g infant was delivered, but after delivery, the patient gained $14 \mathrm{~kg}$ and reported persistent bilateral flank pain over a 5-month period. The patient had a 3-year history of hypertension and dyslipidemia, and was taking atenolol ( $50 \mathrm{mg}$ ), nifedipine $(60 \mathrm{mg})$, and atorvastatin $(10 \mathrm{mg})$ once daily. On admission, her blood pressure was $130 / 70 \mathrm{mmHg}$ and her body mass index (BMI) was $36.9 \mathrm{~kg} / \mathrm{m}^{2}$. She showed Cushingoid features, including truncal obesity, striae cutis, and buffalo hump. Her morning plasma cortisol concentration was $22.04 \mu \mathrm{g} / \mathrm{dL}$ and her plasma adrenocorticotrophic hormone (ACTH) concentration was 12.07 $\mathrm{pg} / \mathrm{mL}$. Her plasma renin activity, plasma aldosterone concentration, and aldosterone-to-renin ratio were within the normal ranges, and the concentrations of other adrenal hormones were unremark-

Copyright (C) 2021 Yeungnam University College of Medicine

This is an Open Access article distributed under the terms of the Creative Commons Attribution Non-Commercial License (http://creativecommons.org/licenses/by-nc/4.0/) which permits unrestricted non-commercial use, distribution, and reproduction in any medium, provided the original work is properly cited. 
able. A low-dose dexamethasone suppression test demonstrated autonomous cortisol excess (Tables 1-3). Contrast-enhanced abdominal computed tomography revealed a $35 \times 28 \mathrm{~mm}$ hypoattenuating nodule in the right adrenal gland (Fig. 1), and in venous and delayed phases showed significant enhancement and rapid washout, which was consistent with a cortical adenoma. We, therefore, diagnosed adrenal CS. A laparoscopic right adrenalectomy was performed and pathological examination revealed that the mass was an adrenal cortical adenoma. On the day of surgery, $200 \mathrm{mg}$ of intravenous hydrocortisone was administered to avoid an adrenal crisis, and the dose was gradually tapered off. Four months after the surgery, the patient resumed menstruation. The patient's body mass decreased from $92.6 \mathrm{~kg}$ before surgery to $70 \mathrm{~kg} 6$ months later. Long-term follow-up of the patient showed that her blood pressure had improved. She was able to stop taking antihypertensive drugs and hydrocortisone 2 years after surgery.

\section{Case 2}

A 34-year-old woman attended our outpatient department because of weight gain and easy bruising. She was diagnosed with gestational diabetes during her 25 th week of gestation and she de- livered a 2,200-g female infant by cesarean section during the 37 th week. She returned to the hospital 8 months after delivery because she had not experienced menstruation, even after stopping breastfeeding, and had gradually gained weight and noticed multiple bruises. Her blood pressure was 170/106 mmHg and her BMI was $24.6 \mathrm{~kg} / \mathrm{m}^{2}$. On physical examination, she had a moon face, buffalo hump, multiple bruises, and abdominal striae. Laboratory investigations revealed morning plasma cortisol and ACTH concentrations suggestive of ACTH-dependent hypercortisolism (Tables 1,2). Low-dose dexamethasone suppression testing was not associated with a reduction in plasma cortisol concentration, but high-dose dexamethasone suppression testing was, which was consistent with a diagnosis of Cushing disease (CD) (Table 3). Pituitary magnetic resonance imaging revealed a $3 \times 4 \times 6 \mathrm{~mm}$ hypointense nodule on the left side of the pituitary gland (Fig. 2). Endonasal pituitary adenomectomy was performed via an endonasal transsphenoidal approach, and the pathological finding was an ACTH-producing pituitary adenoma (World Health Organization grade I). One day following surgery, her plasma ACTH concentration had decreased from 68.48 to $20.43 \mathrm{pg} / \mathrm{mL}$. In addition, her plasma cortisol concentration had decreased to $1.18 \mu \mathrm{g} /$

Table 1. Summary of the clinical characteristics of the reported cases

\begin{tabular}{|c|c|c|c|c|c|c|c|c|c|}
\hline Case & $\begin{array}{l}\text { Principal } \\
\text { complaint }\end{array}$ & $\begin{array}{c}\text { Physical } \\
\text { examination }\end{array}$ & $\begin{array}{c}\mathrm{BMl} \\
\left(\mathrm{kg} / \mathrm{m}^{2}\right)\end{array}$ & $\begin{array}{c}\text { Blood pressure } \\
(\mathrm{mmHg})\end{array}$ & Imaging result & Diagnosis & $\begin{array}{l}\text { Maternal } \\
\text { outcome }\end{array}$ & $\begin{array}{l}\text { Pregnancy } \\
\text { outcome }\end{array}$ & Management \\
\hline 1 & $\begin{array}{l}\text { Bilateral flank } \\
\text { pain, weight } \\
\text { gain }\end{array}$ & $\begin{array}{l}\text { Truncal obesity, } \\
\text { striae cutis, } \\
\text { buffalo hump }\end{array}$ & 36.9 & $140 / 100$ & $\begin{array}{l}\text { Right adrenal } \\
\text { adenoma } \\
(35 \times 28 \mathrm{~mm})\end{array}$ & $\begin{array}{l}\text { Adrenal Cushing } \\
\text { syndrome }\end{array}$ & $\begin{array}{l}\text { Pulmonary arterial } \\
\text { hypertension }\end{array}$ & $\begin{array}{c}\text { LBW }(1,720 \mathrm{~g})^{\text {a) }} \text {, } \\
\text { preterm birth } \\
(35+1 \text { wk })^{b)}\end{array}$ & $\begin{array}{c}\text { Laparoscopic } \\
\text { right adre- } \\
\text { nalectomy }\end{array}$ \\
\hline 2 & Weight gain & $\begin{array}{l}\text { Moon face, buf- } \\
\text { falo hump, } \\
\text { purple striae }\end{array}$ & 24.6 & $170 / 106$ & $\begin{array}{l}\text { Pituitary mi- } \\
\text { croadenoma } \\
(3 \times 4 \times 6 \mathrm{~mm})\end{array}$ & Cushing disease & Gestational diabetes & s LBW $(2,200 \mathrm{~g})^{\mathrm{a})}$ & $\begin{array}{c}\text { Pituitary ade- } \\
\text { nomectomy } \\
\text { via a TSA }\end{array}$ \\
\hline
\end{tabular}

BMI, body mass index; LBW, low birth weight; TSA, transsphenoidal approach.

${ }^{a)}$ Weight at birth less than 2,500 g, regardless of gestational age. ${ }^{\text {b) }}$ Babies born alive before 37 weeks of pregnancy.

Table 2. Laboratory data of the reported cases

\begin{tabular}{lcccccc}
\hline Case & $\begin{array}{c}\text { Fasting plasma glucose } \\
(70-99 \mathrm{mg} / \mathrm{dL})\end{array}$ & $\begin{array}{c}\text { Plasma sodium } \\
(136-145 \mathrm{mmo} / \mathrm{L})\end{array}$ & $\begin{array}{c}\text { Plasma potassium } \\
(3.5-5.0 \mathrm{mmol} / \mathrm{L})\end{array}$ & $\begin{array}{c}\text { Plasma ACTH } \\
(10-60 \mathrm{pg} / \mathrm{mL})\end{array}$ & $\begin{array}{c}\text { Basal plasma cortisol } \\
(9.4-26.1 \mu \mathrm{\mu g} / \mathrm{dL})\end{array}$ & $\begin{array}{c}24-H r \\
(1.49-8.20 \mu \mathrm{\mu g} / \mathrm{day})\end{array}$ \\
\hline 1 & 100 & 148 & 3.2 & 12.07 & 22.04 & 40.02 \\
2 & 99 & 140 & 3.8 & 149.20 & 48.97 & 85.87 \\
\hline
\end{tabular}

ACTH, adrenocorticotropic hormone.

Table 3. Results of dexamethasone suppression testing

\begin{tabular}{|c|c|c|c|c|c|c|c|c|c|}
\hline \multirow{3}{*}{ Variable } & \multirow{2}{*}{\multicolumn{3}{|c|}{$\begin{array}{c}\text { Case } 1 \\
\text { Low-dose dexamethasone test }\end{array}$}} & \multicolumn{6}{|c|}{ Case 2} \\
\hline & & & & \multicolumn{3}{|c|}{ Low-dose dexamethasone test } & \multicolumn{3}{|c|}{ High-dose dexamethasone test } \\
\hline & Basal & $24 \mathrm{hr}$ & $48 \mathrm{hr}$ & Basal & $24 \mathrm{hr}$ & $48 \mathrm{hr}$ & Basal & $24 \mathrm{hr}$ & $48 \mathrm{hr}$ \\
\hline Serum cortisol $(\mu \mathrm{g} / \mathrm{dL})$ & 14.85 & 15.02 & 21.22 & 25.99 & 13.71 & 8.95 & 24.63 & 1.10 & 1.91 \\
\hline $24-\mathrm{Hr}$ urine-free cortisol ( $\mu \mathrm{g} /$ day) & 40.02 & 35.48 & 38.51 & 28.08 & 14.41 & 1.51 & 25.78 & 2.93 & 1.12 \\
\hline 17-OHCS (mg/dL) & 30.2 & 27.8 & 30.1 & 22 & 18 & 9 & 20 & 8 & 6 \\
\hline
\end{tabular}

17-OHCS, 17-hydroxycorticosteroids. 

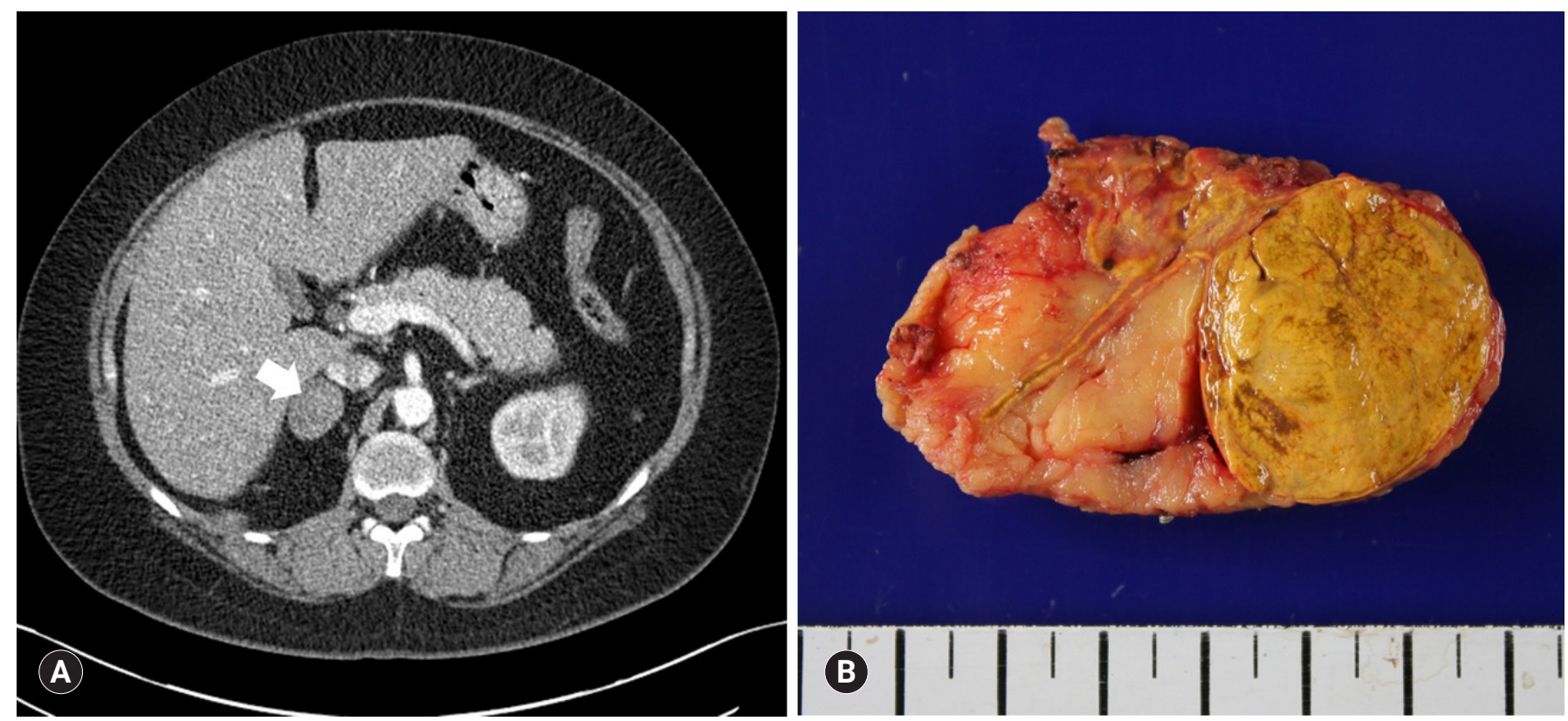

Fig. 1. (A) Abdominal computed tomography reveals a $35 \times 28 \mathrm{~mm}$, hypoattenuating mass (arrow) in the right adrenal gland. (B) The excised right adrenal gland shows a well circumscribed, yellowish mass.
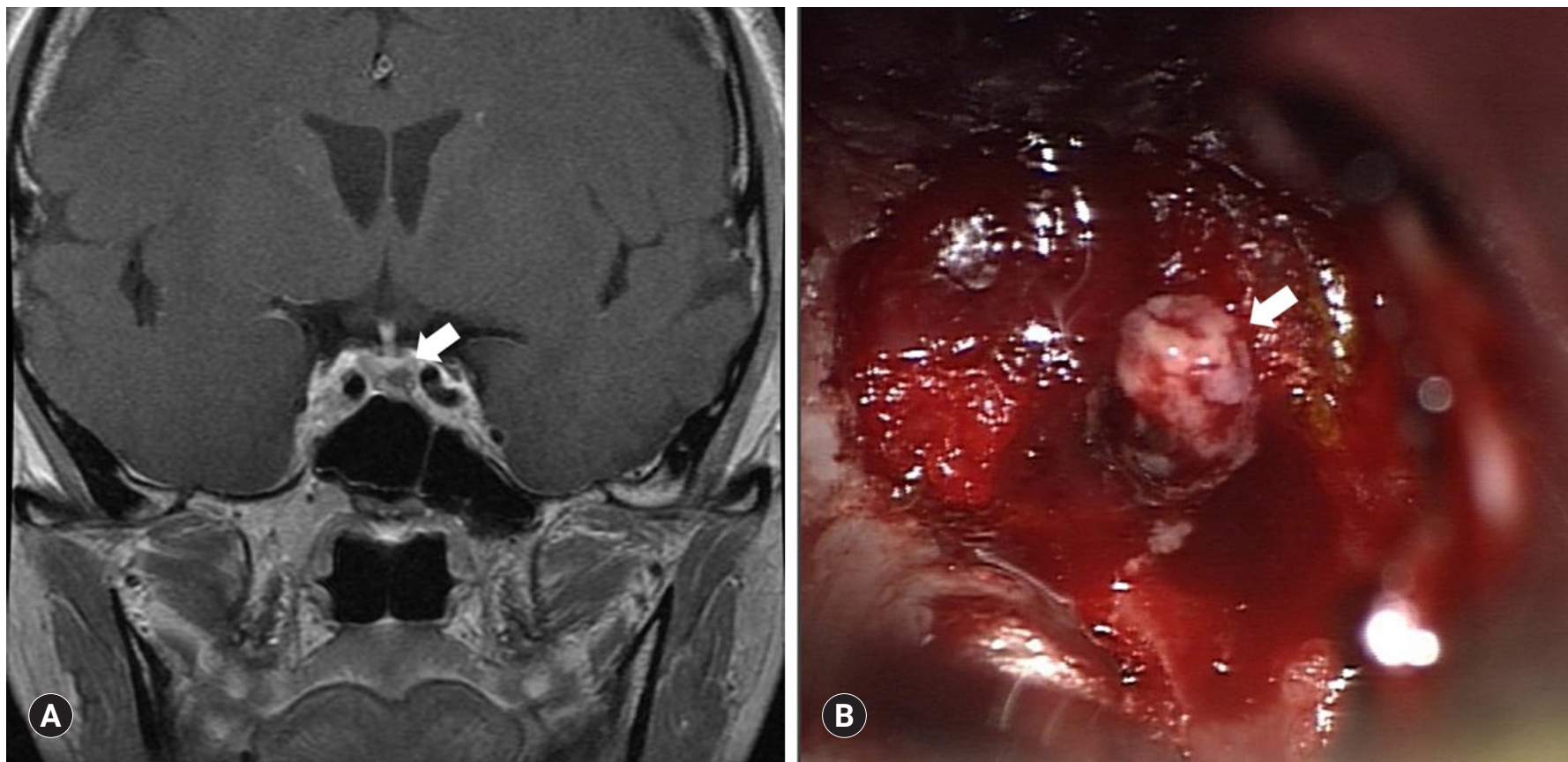

Fig. 2. (A) Pituitary magnetic resonance imaging shows a $3 \times 4 \times 6 \mathrm{~mm}$, hypointense nodule (arrow) in the left side of the pituitary gland. (B) The intraoperative photograph shows a grayish pink nodule (arrow) in the left side of the pituitary gland.

$\mathrm{dL}$, and thus hydrocortisone treatment was initiated. The patient's blood pressure had normalized, and antihypertensive medication and hydrocortisone administration were stopped 3 months after surgery.

\section{Discussion}

When women are diagnosed with CS less than 12 months after delivery, they are empirically considered to have had active CS during pregnancy, with a high probability of concomitant hyper- 
cortisolism during pregnancy [3]. Herein, we have reported two patients in whom CS was diagnosed 5 and 8 months after delivery, which is consistent with them having had active CS during pregnancy.

Chronic hypercortisolemia inhibits both the action of gonadotropin-releasing hormone $(\mathrm{GnRH})$ in the gonads and $\mathrm{GnRH}$ secretion from the hypothalamus [1]. Therefore, women with untreated CS rarely become pregnant. In those who do become pregnant, 55\% have ACTH-independent CS, whereas ACTH-independent CS accounts for a relatively small proportion in non-pregnant women [3]. It has been suggested that in $\mathrm{CD}$, there is hypersecretion of cortisol and androgens, which interferes with the gonadal axis, causing amenorrhea in over $70 \%$ of patients, whereas adrenal tumors almost exclusively hypersecrete cortisol [4]. Therefore, the second patient reported herein, in which CD had likely been present during pregnancy, had a relatively rare condition.

The diagnosis of CS in pregnancy is quite difficult for many reasons. First, due to its very low incidence, a high degree of clinical suspicion is required [1]. Second, the clinical signs of hypercortisolism (weight gain, fatigue, hypertension, and hyperglycemia) overlap with the physiological changes that characterize pregnancy $[2,5]$. Therefore, CS is often not diagnosed until the second trimester [6]. However, although many of the symptoms overlap, the occurrence of pathological fracture should provoke a CS work-up [7]. In the present patients, the symptoms reported are common features of pregnancy, meaning that it would have been difficult to diagnose CS earlier.

The diagnosis of CS during pregnancy is also hampered by the changes in the hypothalamic-pituitary-adrenal (HPA) axis that normally occur [8]. Plasma ACTH and cortisol concentrations and urinary free cortisol (UFC) concentration are high during normal pregnancies, which makes biochemical diagnosis more challenging [8]. However, a recent study showed that late-night salivary cortisol concentration is higher in patients with CS than in pregnant women [9]; therefore, the use of a combination of UFC and late-night salivary cortisol is recommended for the diagnosis of CS during pregnancy.

CS during pregnancy is associated with poor maternal and fetal outcomes [2]. Patients with active CS tend to deliver earlier than those whose CS has been corrected and are more likely to undergo cesarean section. They also more frequently experience complications of pregnancy, including gestational diabetes, hypertension, and preeclampsia. In addition, fetal complications, such as fetal loss, fetal distress, preterm birth, and low birth weight, are more frequent in the presence of active maternal CS [3]. In both the patients reported here, maternal complications occurred during preg- nancy and one neonate was born preterm and both were a low birth weight.

The management of pregnant women with CS is similar to that of non-pregnant patients. For both ACTH-independent and ACTH-dependent CS, surgical treatment should ideally be performed during the second trimester, before the 24th week of gestation. For ACTH-independent CS, which accounts for $55 \%$ of the cases of CS during pregnancy, adrenal surgery appears to be more successful than medical therapy. For pregnant women with CD, transsphenoidal surgery or medical therapy (generally using metyrapone) have both been used [10]. In addition to the specific treatment of CS, any comorbidities should be treated, including diabetes and hypertension [2]. After the surgical treatment of both of the patients reported herein, their symptoms resolved.

As in the cases reported herein, the diagnosis of CS during pregnancy is difficult because of its low incidence, the overlapping clinical signs, and the changes that occur in the HPA axis during normal pregnancy. However, because CS is associated with higher incidences of maternal and fetal complications, early diagnosis is important. Therefore, when pregnant women present with suspicious symptoms, such as pathological fracture, physicians should consider whether they might be hypercortisolemic.

\section{Acknowledgments}

\section{Conflicts of interest}

No potential conflict of interest relevant to this article was reported.

\section{Author contributions}

Conceptualization: all authors; Data curation: HBK; Formal analysis: HSK; Methodology: MKK; Resources: EK, KSA, NKK; Supervision: HSK; Validation: MKK; Writing-original draft: HBK; Writing-review \& editing: HSK, MKK.

\section{ORCID}

Han Byul Kim, https://orcid.org/0000-0002-5024-7496

Mi Kyung Kim, https://orcid.org/0000-0001-5750-3598

El Kim, https://orcid.org/0000-0002-7664-6030

Keun Soo Ahn, https://orcid.org/0000-0001-8738-8009

Hye Soon Kim, https://orcid.org/0000-0001-6298-3506

Nam Kyung Kim, https://orcid.org/0000-0002-5363-6817

\section{References}

1. Lado-Abeal J, Rodriguez-Arnao J, Newell-Price JD, Perry LA, Grossman AB, Besser GM, et al. Menstrual abnormalities in 
women with Cushing's disease are correlated with hypercortisolemia rather than raised circulating androgen levels. J Clin Endocrinol Metab 1998;83:3083-8.

2. Lindsay JR, Jonklaas J, Oldfield EH, Nieman LK. Cushing's syndrome during pregnancy: personal experience and review of the literature. J Clin Endocrinol Metab 2005;90:3077-83.

3. Caimari F, Valassi E, Garbayo P, Steffensen C, Santos A, Corcoy $\mathrm{R}$, et al. Cushing's syndrome and pregnancy outcomes: a systematic review of published cases. Endocrine 2017;55:555-63.

4. Polli N, Pecori Giraldi F, Cavagnini F. Cushing's syndrome in pregnancy.J Endocrinol Invest 2003;26:1045-50.

5. Aron DC, Schnall AM, Sheeler LR. Cushing's syndrome and pregnancy. Am J Obstet Gynecol 1990;162:244-52.

6. Andreescu CE, Alwani RA, Hofland J, Looijenga LH, de Herder WW, Hofland LJ, et al. Adrenal Cushing's syndrome during pregnancy. Eur J Endocrinol 2017;177:K13-20.
7. Brue T, Amodru V, Castinetti F. Management of endocrine disease. Management of Cushing's syndrome during pregnancy: solved and unsolved questions. Eur J Endocrinol 2018;178: R259-66.

8. Lindsay JR, Nieman LK. The hypothalamic-pituitary-adrenal axis in pregnancy: challenges in disease detection and treatment. Endocr Rev 2005;26:775-99.

9. Lopes LM, Francisco RP, Galletta MA, Bronstein MD. Determination of nighttime salivary cortisol during pregnancy: comparison with values in non-pregnancy and Cushing's disease. Pituitary 2016;19:30-8.

10. Sammour RN, Saiegh L, Matter I, Gonen R, Shechner C, Cohen $\mathrm{M}$, et al. Adrenalectomy for adrenocortical adenoma causing Cushing's syndrome in pregnancy: a case report and review of literature. Eur J Obstet Gynecol Reprod Biol 2012;165:1-7. 